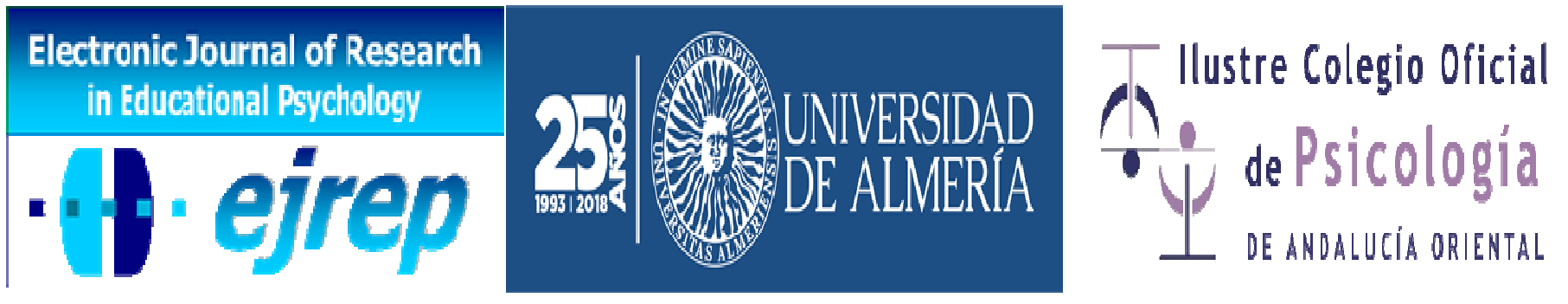

\title{
Is there any relation between alexithymia in parents and children? Effects on children's quality of life
}

\section{Esther Castañeda López ${ }^{1}$, Cecilia Peñacoba Puente $^{2}$, Silvia Benito Moreno ${ }^{3}$}

\footnotetext{
${ }^{1}$ Department of Psychology, Centro Universitario ESCUNI (Adscrito UCM), Madrid

${ }^{2}$ Department of Psychology, Rey Juan Carlos University, Alcorcón, Madrid

${ }^{3}$ Orientadora de la Consejería de Educación, Comunidad de Madrid, Madrid
}

\section{España}

Correspondence: Esther Castañeda López. Avenida Nuestra Señora de Fátima 102. Madrid. E-mail: ecastaneda@escuni.es

(C) Universidad de Almería and Ilustre Colegio Oficial de la Psicología de Andalucía Oriental (Spain) 


\begin{abstract}
Introduction. The study of alexithymia in children (especially in healthy children), contrary to adult populations, has not been studied extensively, despite its relevant relation to health and quality of life. The purpose of this study was to analyze, in healthy children, the relation between children's alexithymia and their parents' alexithymia, the relation between children's alexithymia and children's quality of life, as well as to understand whether this relation is mediated by parents' alexithymia.
\end{abstract}

Method. Alexithymia and quality of life questionnaires were administered to children aged 812, and Alexithymia questionnaires were administered to their parents, father or mather who was the main care-takers. Correlational study. Means and standard deviations of the all variables were described. Pearson' correlations, t-tests, multiple linear regressions and mediation analysis using ordinary least squares multiple regression and Sobel test were employed.

Results. Results indicated a significant relation between Alexithymia dimensions for children and parents (except for the externally oriented thinking dimension). Children's difficulty identifying feelings and difficulty describing feelings predict all their quality of life dimensions (except for physical well-being). Results further indicated that this relation was partially mediated by parent's difficulty describing feelings for some of the children's quality of life dimensions.

Conclusion. These findings have important practical implications regarding the planning of educational school programs for children. Specifically, within an educational system according to competences, identification and emotional expression strategies should be incorporated for the enhancement of quality of life in children and the prevention of alexithymia and somatization problems in adults.

Keywords: alexithymia; children; parents; quality of life. 


\section{Resumen}

Introducción. El estudio de la alexitimia en niños (especialmente en niños sanos), a diferencia de la población adulta, no ha sido estudiado ampliamente, a pesar de su estrecha relación con la salud y la calidad de vida. El objetivo de este estudio fue analizar por un lado, la relación entre la alexitimia infantil y la alexitimia de sus padres, y por otro lado, la relación entre la alexitimia infantil y la calidad de vida de los niños, así como establecer si esta relación está mediada por la alexitimia de los padres.

Método. Se administraron cuestionarios de alexitmia y calidad de vida a niños de entre 8 y 12 años y un cuestionario de alexitmia a sus padres, padre o madre que fuera la principal figura de cuidados. Se utilizó un diseño correlacional transversal, con análisis descriptivos de las variables de interés, correlaciones de Pearson, T de Student, regresiones lineales, y análisis de mediación empleando análisis de regresión múltiple y el test de Sobel.

Resultados. Los resultados indicaron una relación significativa en las dimensiones de alexitmia entre los niños y los padres (a excepción de la dimensión de pensamiento orientado hacia el exterior). La dificultad de los niños para identificar emociones y la dificultad para describir las emociones predicen todas las dimensiones de calidad de vida (excepto el bienestar físico). Los resultados indicaron además, que esta relación fue parcialmente mediada por la dificultad de los padres para describir las emociones de algunas de las dimensiones de calidad de vida de los niños.

Conclusión. Estos hallazgos tienen importantes implicaciones prácticas con respecto a la planificación de programas educativos para niños. Específicamente, en un sistema educativo en el que se valora la adquisición de competencias, se deben incorporar estrategias de identificación y expresión emocional para mejorar la calidad de vida de los niños y prevenir los problemas derivados de la alexitimia en la población adulta.

Palabras Clave: alexitimia; niños; padres; calidad de vida. 


\section{Introduction}

Alexithymia is a multifaceted construct that was described by Sifneos (1973) as a difficulty identifying and communicating feelings, differentiating feelings and somatic sensations of emotional arousal, and an externally oriented cognitive style. The 20-Item Toronto Alexithymia Scale (TAS-20) (Bagby, Parker, \& Taylor, 1994) has since become the most widely used instrument for assessing alexithymia. The TAS-20 yields three factors (difficulty identifying feelings, difficulty describing feelings, and externally oriented thinking). There is an adaptation of the questionnaire for children (Alexithymia Questionnaire for children; AQC, Rieffe, Osterveld, \& Meerum Terwogt, 2006), which has also been translated and validated into French, Farsi and Italian.

The concept of alexithymia has been associated to somatization disorders, described as a personality trait and hypothesised as a risk factor for the development or persistence of medically unexplained symptoms (Bagby et al., 1994). However, the review ofDe Gucht and Heiser (2003) highlights some of the limitations of these studies, namely including the use of questionnaires that can only check for symptoms, not whether these symptoms are medically explained or not; the inconsistent results found when comparing somatoform conditions to medical and psychiatric controls that may be attributed to confounding variables, or the scarcity of prospective studies.

The study of alexithymia in children is not very abundant, although different authors have pointed out its relevance in the infant stage and have provided data on their prevalence (Joukamaa et al., 2008). Most research in childhood has focused on the study of possible predictors of alexithymia. Childhood abuse has been considered as one of the predictors of alexithymia in the adult population. Most of these studies (Evren, Dalbudak, Ozcelik, \& Oncu, 2009; De Rick \& Vanheule, 2006), have analyzed populations with physical and mental pathology, especially addictions, and have a retrospective design. Nevertheless, the data is not entirely conclusive, so that other authors have found no clear relationship between childhood trauma and alexithymia (Joukamaa et al., 2008; Spitzer et al., 2009).

From a health psychology perspective, there are a few empirical studies to support the clinical hypothesis that alexithymia may be due to disturbances in the early parent-child relationship. These findings serve to strengthen the theory of alexithymia as a developmental pro- 
cess starting in childhood (Joukamaa et al., 2008). Thorberg, Young, Sullivan, \& Lyvers (2011), in a meta-analysis about the relationship between parenting styles and alexithymia, indicated a moderate to strong relationships between maternal care and alexithymia, specifically with two of the three TAS-20 alexithymia dimensions (Difficulties Describing Feelings and Difficulties Identifying Feelings, but not Externally Oriented Thinking). Moderate relationships were observed for both maternal- and paternal-overprotection and alexithymia respectively, and for overprotection (both maternal and paternal) and Difficulties Describing Feelings. However, as is the case of childhood trauma studies, most of the research (Gil, Scheidt, Hoeger, \& Nickel, 2009; Pedrosa et al., 2008; Spitzer et al., 2009), has a retrospective design, being conducted mostly in clinical populations with different pathologies, contemplating patient alexithymia as a differentiating variable from healthy samples, and analyzing the early parent-child relationship as an additional risk factor for alexithymia.

In normative samples, Joukamaa et al. (2003) showed that unwanted children or subjects born into families with many children also exhibited an association with alexithymia in adulthood. Dial Ward (2002) found that poor paternal affective expressiveness is a predictor for alexithymia in young adult males, whereas poor maternal affective expressiveness is a predictor of externally oriented thinking in adult women. Aust, Hartwig, Heuser, \& Bajbouj (2013) in a high alexithymic but healthy community sample found a significantly positive correlation between alexithymia and early emotional neglect. Despite the abundant literature linking early parent-child relationship with alexithymia, it should be noted there is a scarcity of prospective studies, conducted in samples of children. Furthermore, there is little data on alexithymia prevalence in children, except samples with some kind of pathology, with studies in adolescents being more abundant. Joukamaa et al. (2007), as a part of the Northern Finland Birth Cohort 1986 Study, among a representative sample of 15-16-year olds, found that a 10\% of the girls and a $7 \%$ of the boys were alexithymic.

Alexithymia studies in children have focused, following the same approach as in adult samples, on its relation to possible physical complaints, either in samples of healthy children or in children with a physical or mental pathology. In healthy children, Jellesma, Rieffe, Terwogt, \& Westenberg (2009) showed that children with many complaints, compared to children with few complaints, seemed to have higher self-reports of alexithymia. Nasiri, Latifian, \& Rieffe (2009), in elementary school children, found that alexithymia showed a positive as- 
sociation with physical complaints and negative emotions, and a negative association with happiness. Allen, Lu, Tsao, Hayes, \& Zeltzer (2011) showed that depression partially mediated alexithymia and somatization in a sample of healthy children, at least for two dimensions of alexithymia (difficulty identifying and describing feelings). However, Rieffe et al. (2010) noted that there is a unique contribution of alexithymia to the explanation of internalizing symptoms over and above negative mood.

In samples of children and adolescents with physical and mental diseases it has been observed that the prevalence of alexithymia is higher in tension-type headache (Dal Zotto, Toldo, Sartori, \& Battistella, 2011), cancer (Mishra, Maudgal, Theunissen, \& Rieffe, 2012), chronic fatigue syndrome (van de Putte, Engelbert, Kuis, Kimpen, \& Uiterwaal, 2007), chronic renal failure children (Keskin \& Bilge, 2009), borderline personality disorder (BPD) (Loas, Speranza, PhamScottez, Perez Diaz, \& Corcos, 2012), and eating disorders (Hosseinzadeh, Hooman, Salehi, \& Kooshki, 2013), compared to healthy children and adolescents.

Finally, other studies have focused on the relationship between parental alexithymia (or other family members) and childhood alexithymia, although the results are not conclusive. In healthy children, Mahler, Barnow, Freyberger and Grabe (2011), revealed that the mothers' alexithymia and the fathers' alexithymia independently predict the child's alexithymia. However, Luminet and Lenoir (2007), in an experimental task with children of 3 or 5-years-old selected as a function of parents' alexithymia level, showed that 3-year-old children in the alexithymic parents' group had a significantly lower score for identification and differentiation tasks, but this deficit was not observed for 5-year-old children. In children with physical or mental pathology, Mishra et al. (2012) examined the levels of alexithymia in children with cancer, in siblings of children with cancer, and in healthy controls. The highest level of alexithymia was reported by children diagnosed with cancer, followed by their siblings. Szatmari et al. (2008) show that parents of children with Autism Spectrum Disorder (ASD) score higher than controls on the TAS-20 total score, and within the ASD group, children of fathers with high alexithymia score higher on repetitive behaviour symptoms compared to children of fathers with low alexithymia. However, Dal Zotto et al. (2011), in patients aged from 8 to 15 suffering from tension-type headaches, did not find significant a correlation between alexithymia rates in the children/preadolescents and in their mothers. 


\section{Objetives and hypothesis}

After reviewing the literature we found few studies analyzing the relationship between parental alexithymia and childhood alexithymia in healthy children and most studies focuses on the relation between alexithymia and pathology and somatization, so our study has the following aims: First, to analyze the relationship between the parental alexithymia and childhood alexithymia in a healthy sample. Second, to identify the role of childhood alexithymia on children's quality of life. Third, to assess the possible mediating role of parental alexithymia between childhood alexithymia and children's quality of life.

\section{Method}

\section{Participants}

A total of 265 children and parents (main care-taker) participated in this study. Mean age of children was 9.7 years ( $\mathrm{SD}=1.22$; ranging from 8 to 12 years) and $53.9 \%$ were girls. Children were drawn from various public elementary schools in Madrid (Spain), of second and third cycle. The second cycle (third and fourth grade) group comprised 137 children (60 boys, 77 girls, mean age $8.72 ; \mathrm{SD}=.65$ years; ranging from 8 to 10 years). The third cycle (fifth and sixth grade) group comprised 128 children (63 boys and 65 girls, mean age 10.74 years, $\mathrm{SD}=.72$, ranging from 10 to 12 years). Parental consent was obtained for all participants. With regards to the parents, $86.4 \%$ of main care-takers were the mothers, whilst $13.6 \%$ were the fathers. Mean age was 41.31 years $(\mathrm{SD}=4.78$, ranging from 28-64).

\section{Instruments}

\section{For parents: Alexithymia}

We used the Spanish version (Páez, Velasco, \& Gonzalez, 1999) of the Toronto Alexithymia Scale (TAS-20; Bagby et al., 1994). The TAS-20 is a 20 item self-report measure for alexithymia with three subscales: (1) difficulty identifying feelings (DIF), (2) difficulty describing feelings (DDF), and (3) tendency toward externally oriented thinking (EOT). The TAS-20 has 20 items (seven, five and eight items for each subscale respectively) using a 6pointLikert scale (from 0 to 5 ). It is the most widely used measure for alexithymia, and has been validated in numerous studies across several cultures. The TAS-20 total scores and DIF and DDF factors correlate positively with self-reported physical symptoms (Taylor \& Bagby, 
2004), while the correlation with the EOT factor is not always evident (Grabe, Spitzer, \& Freyberger, 2004).

\section{For children: Alexithymia}

We have administered the Alexithymia Questionnaire for Children (AQC; Rieffe et al., 2006), consistent with the original adult questionnaire for alexithymia (TAS-20; Bagby et al., 1994). The authors identified three factors: a) Difficulty Identifying Feelings (DIF, 7 items), Difficulty Describing Feelings (DDF, 5 items) and Externally-Oriented Thinking (EOT, 8 items). The internal consistency coefficient (Cronbach's Alpha) was .71. In this sense, Cronbach's Alpha was .73 for DIF and .75 for DDF meanwhile for EOT was .29. The original English AQC version was translated into Spanish by a bilingual psychologist. Then, it was sent to a cooperating primary school, where one teacher reviewed the items in a way appropriate for primary school-aged children. This version was discussed with the teaching staff until consensus was reached. This new version was then sent back to the other bilingual psychologist who back-translated the items and compared them with the original English version. If the content of an item had changed, additional revisions were made. The last version was sent to the co-operating school again for their approval. Children were instructed to score each item on a three-point response scale $(0=$ not true; $1=$ a bit true; $2=$ true $)$, the same as the AQC (Rieffe et al., 2006), in order to simplify the response scale for children and provide clear verbal labels with each answer category.

\section{For children: Health-Related Quality of Life}

We used the Spanish version (Aymerich et al., 2005) of the Kidscreen 52 items HRQOL Health Questionnaire for Children and Adolescents (Ravens-Sieberer et al., 2005). This questionnaire was developed as a self-report measure applicable to healthy and chronically ill children and adolescents aged between 8 and 18 years. The instrument is composed by ten dimensions: physical well-being, 5 items (Cronbach's Alpha $=.80$ ); psychological well-being, 6 items(Cronbach's Alpha $=.89)$ moods and emotions, 7 items (Cronbach's Alpha $=.86)$, self-perception, 5 items (Cronbach's Alpha $=.79)$, autonomy, 5 items (Cronbach's Alpha $=.84)$, parent relation and home life, 6 items $($ Cronbach's Alpha $=.89)$, financial resources, 3 items (Cronbach's Alpha $=.89$ ), social support and peers, 6 items (Cronbach's Alpha $=.85)$, school environment, 6 items $($ Cronbach's Alpha $=.87)$ and social acceptance, 3 items (Cronbach's Alpha $=.80)$. The Kidscreen 52 items instrument has been used simultaneously in 13 European countries in the cross-cultural harmonisation and development of the 
measure (Ravens-Sieberer et al., 2005). The answer scale of this ranged from $1=$ never to $5=$ always or from $1=$ nothing to $5=$ very much. Concurrent validity of AQC has been tested using information on Kidscreen 52 items edition.

\section{Procedure}

Firstly, we developed a pilot study with a group of 4 children aged 8 to 12 to see the difficulties in management and the adequacy of the design of each of the items of the full protocol (socio-demographics, alexithymia and quality of life). No changes were done after piloting the instrument.

Three schools were selected based on location and convenience. At each site, the management of the school and teachers were informed about the study. The exclusion criterion was to have been diagnosed with a physical illness or mental disorder when the study commenced. Then, parents were approached and informed about the study. If parents were interested in having their children participate, the researcher explained the informed consent form to the parent and asked them to sign. The researcher then asked the parent to fill out the TAS20 questionnaire and some socio-demographic items (age and gender).

A list of children's names for which parent consent was obtained was developed for each school. A number was assigned to each student to ensure anonymity. At the time of data collection, during the class, children who participated in the study were called leave the classroom (to a separate room) in subgroups of 10 children. The researcher read, explained and instructed the different questionnaires (socio-demographic, alexithymia and quality of life). Once all the children completed all questionnaires, the researcher made sure data collection had been completed and that no items had been left unanswered, if this had occurred the researcher would resolve any doubts the child may have so that the item could be completed.

This procedure was the same for each group in every school; however, the order of presentation of the questionnaires was counterbalanced for each group administration so as to minimize order effects. Administration and completion of the questionnaires took approximately 30 minutes. Upon completion of the questionnaires, the parents of the children were given a more detailed individual information report regarding their participation in this study. 
This study operated in accordance with the ethical guidelines set forth by the American Psychological Association.

\section{Datal Analysis}

Means and standard deviations of the all subscales were described. The relationships between socio-demographic variables (age and gender) and the target variables (childhood alexithymia and children's quality of life) were explored by conducting the appropriate test for each variable (Pearson' correlations, t-tests). Pearson correlation was used to analyze the relationship between all the target variables (childhood alexithymia, children's quality of life and parental alexithymia). The childhood alexithymia predictors of children's quality of life dimensions were examined with ten multiple linear regressions (one for each of the quality of life dimensions). All sociodemographic variables that might exert a confounding effect on the regression analyses were included. To test for the presence of mediating effects, we conducted an ordinary least squares multiple regression analysis (Baron \& Kenny, 1986; Preacher, Rucker, \& Hayes, 2007). Because a reduced beta weight in itself does not seem to be indicative of significance, and this assumption of the Baron and Kenny method (1986) has been criticized, we additionally performed the Sobel test to demonstrate partial mediation (Sobel, 1982). Differences were considered significant at a p level $<.05$. The statistical package SPSS version 17.0 was used for the analyses.

\section{Results}

\section{Descriptive and Preliminary Analyses}

\section{Descriptive information}

Table 1 shows the descriptive statistics and correlations among each of the variables assessed. Regarding alexithymia in children, DDF received the highest average scores, whereas DIF received the lowest average score. Regarding alexithymia in parents, EOT received the highest average scores, whereas DDF received the lowest average score, with a very similar result to DIF. Scores on the Kidscreen dimensions ranged from 3.83 to 4.30 , which is high within the allowable range for 1-5. The lowest scores were obtained for the dimensions of financial resources and autonomy, and the highest for psychological quality of life. 
Table 1. Means, standard deviations (SD), and Pearson correlation coefficients for each of the variables assessed

\begin{tabular}{|c|c|c|c|c|c|c|c|c|c|c|c|c|c|c|c|c|}
\hline & Mean (SD) & 2 & 3 & 4 & 5 & 6 & 7 & 8 & 9 & 10 & 11 & 12 & 13 & 14 & 15 & 16 \\
\hline 1. Difficulty identify feelings (children) & $0.73(0.45)$ & $.49 * *$ & .07 & $.26 * *$ & $.23 * *$ & .06 & $-.13^{*}$ & $-.34 * *$ & $-.48 * *$ & $-.36 * *$ & $-.24 * *$ & $-.35 * *$ & $-.23 * *$ & $-.18 * *$ & $-.26 * *$ & $-.29 * *$ \\
\hline 2. Difficulty describing feelings (children) & $0.89(0.49)$ & - & .01 & $.27 * *$ & $.25 * *$ & .02 & -.08 & $-.24 * *$ & $-.36 * *$ & $-.28 * *$ & $-.23 * *$ & $-.27 * *$ & $-.22 * *$ & $-.16 * *$ & $-.21 * *$ & $-.24 * *$ \\
\hline 3. External oriented thinking (children) & $0.83(0.30)$ & & - & .10 & .09 & .05 & -.09 & -.06 & -.06 & .01 & -.05 & -.11 & -.12 & -.10 & -.10 & -.05 \\
\hline 4. Difficulty identify feelings (parents) & $7.85(6.41)$ & & & - & $.60 * *$ & $.35^{* *}$ & -.00 & $-.14 *$ & $-.18 * *$ & $-.18 * *$ & -.04 & -.07 & $-.14 *$ & -.04 & -.12 & -.08 \\
\hline 5. Difficulty describing feelings (parents) & $7.31(4.94)$ & & & & - & $.42 * *$ & -.02 & $-.14 *$ & $-.17 * *$ & $-.19 * *$ & $-.13 *$ & -.06 & $-.16^{*}$ & -.05 & $-.14 *$ & -.08 \\
\hline 6. External oriented thinking (parents) & $12.23(4.78)$ & & & & & - & -.04 & -.01 & -.08 & -.06 & .02 & .11 & -.08 & .00 & .05 & -.05 \\
\hline 7. Physical Well-being & $4.03(0.73)$ & & & & & & - & $.49 * *$ & $.28 * *$ & $.28 * *$ & $.37 * *$ & $.27 * *$ & $.39 * *$ & $.42 * *$ & $.31 * *$ & $.18^{* *}$ \\
\hline 8. Psychological Well-being & $4.30(0.68)$ & & & & & & & - & $.63^{* *}$ & $.49 * *$ & $.67 * *$ & $.64 * *$ & $.35 * *$ & $.54 * *$ & $.63 * *$ & $.24 * *$ \\
\hline 9. Moods and Emotions & $4.06(0.79)$ & & & & & & & & - & $.54 * *$ & $.54 * *$ & $.55 * *$ & $.31 * *$ & $.36^{* *}$ & $.50 * *$ & $.38 * *$ \\
\hline 10. Self-Perception & $4.16(0.68)$ & & & & & & & & & - & $.43 * *$ & $.47 * *$ & $.23 * *$ & $.38 * *$ & $.49 * *$ & $.33 * *$ \\
\hline 11. Autonomy & $3.83(0.86)$ & & & & & & & & & & - & $.63 * *$ & $.39 * *$ & $.54 * *$ & $.59 * *$ & $.15^{*}$ \\
\hline 12. Parent Relations and Home Life & $4.28(0.79)$ & & & & & & & & & & & - & $.43 * *$ & $.49 * *$ & $.60 * *$ & $.25^{* *}$ \\
\hline 13. Financial Resources & $3.63(1.12)$ & & & & & & & & & & & & - & $.41 * *$ & $.32 * *$ & $.29 * *$ \\
\hline 14. Social Support and Peers & $4.06(0.76)$ & & & & & & & & & & & & & - & $.51 * *$ & $.30 * *$ \\
\hline 15. School Environment & $4.15(0.79)$ & & & & & & & & & & & & & & - & $.22 * *$ \\
\hline 16. Social Acceptance (Bullying) & $4.11(0.93)$ & & & & & & & & & & & & & & & - \\
\hline
\end{tabular}

$*_{p}<0.05 ; *_{p}<0.01$ 


\section{Control variables}

There was a significant main effect of gender on physical quality of life ( $p=.014)$, with the boys (mean $4.15, \mathrm{SD}=.73$ ) showing greater scores than the girls (mean 3.93, $\mathrm{SD}=.71$ ). With regards to age, significant main affects were found to DIF $\left(\mathrm{r}^{2}=-.14, p=.02\right)$, financial resources $\left(r^{2}=.23, p<.000\right)$ and social support and peers $\left(r^{2}=.14, p=.02\right)$. No other significant associations were found.

\section{Correlations among variables}

As shown in Table 1, in children, DIF showed a significant positive correlation with DDF, but none of these subscales showed a significant correlation with EOT. In the case of alexithymia in parents, the three subscales showed positive significant correlations among them. When the relationship between childhood and parental alexithymia was analyzed, significant positive correlations were observed between DIF and DDF, whereas no relation was observed between children's EOT and parental EOT. With regards to the relation between quality of life and childhood alexithymia, DIF showed significant relations with all ten dimensions of quality of life, and DDF showed significant relations with all quality of life dimensions except for physical quality of life. As expected, all correlations were negative. EOT did not show correlation with any quality of life dimensions. With regards to the relationship between children's quality of life and parental alexithymia, some negative relations were observed in the case of DIF and DDF with psychological well-being, moods and emotions, selfperception and financial resources. Additionally, in the case of DDF significant relations were found to autonomy and school environment. All correlations were negative. No significant relation between EOT and quality of life dimensions were found. Finally, all quality of life dimensions showed positive significant correlations among them.

\section{Regression of childhood alexithymia in children's quality of life}

With regards to the weight of the different dimensions of childhood alexithymia on children's quality of life (see Table 2), DIF and DDF were significant predictors of all quality of life dimensions, except for physical well-being; in the case of DIF this was apparent once age was adjusted for. 
Table 2. Predicting children's quality of life dimensions from DIF and DDF (only significant findings are presented)

\begin{tabular}{lcccc}
\hline Quality of life dimensions & \multicolumn{2}{c}{$D I F$} & \multicolumn{2}{c}{$D D F$} \\
\hline & Beta & $\mathrm{R}^{2}$ & Beta & $\mathrm{R}^{2}$ \\
\hline & & & & \\
Psychological Well-being & $-.340^{* * *}$ & 0.12 & $-.239^{* * *}$ & 0.06 \\
Moods and Emotions & $-.483^{* * *}$ & 0.23 & $-.362^{* * *}$ & 0.13 \\
Self-Perception & $-.361^{* * *}$ & 0.13 & $-.277^{* * *}$ & 0.08 \\
Autonomy & $-.234^{* * *}$ & 0.06 & $-.230^{* * *}$ & 0.05 \\
Parent Relations and Home Life & $-.337^{* * *}$ & 0.13 & $-.266^{* * *}$ & 0.07 \\
Financial Resources & $-.193^{* *}$ & 0.09 & $-.215^{* * *}$ & 0.04 \\
Social Support and Peers & $-.166^{* *}$ & 0.05 & $-.158^{* *}$ & 0.02 \\
School Environment & $-.282^{* * *}$ & 0.08 & $-.205^{* *}$ & 0.04 \\
Social Acceptance (Bullying) & $-.284^{* * *}$ & 0.08 & $-.236^{* *}$ & 0.06 \\
& & & & \\
\hline
\end{tabular}

$*^{* *} p<0.01 ; * * * p<0.001$ Note: DIF: Difficulty Identifying Feelings, DDF: Difficulty Describing Feelings

EOT had no significant effect on any of the quality of life dimensions, although it almost reaches significance for parent relation and home life (p.=.059), financial resources (p.=.055), and school environment ( $p .=.088)$.

\section{Mediation of Parental Alexithymia}

Aiming to analyse the possible mediating effect of parental alexithymia in the relation between childhood alexithymia and children's quality of life, we proceeded to perform the following mediation analyses.

Several preconditions must be met to assess whether a variable has a mediating effect, establishing: (a) significant relationships between the predictor variables (childhood alexithymia dimensions) and the mediator (parental alexithymia dimensions), (b) significant relationships between the predictor variables and the outcome variables (childhood alexithymia dimensions and children's quality of life dimensions), and (c) significant relationships between the mediator variable and the outcome variables (Holmbeck, 1997). These preconditions were assessed with Pearson's correlations among the variables of interest. This analysis 
allowed us to identify the relevant variables to introduce in the subsequent regression analyses (see Table 3).

Table 3. Preconditions for mediation analysis

\begin{tabular}{|c|c|c|}
\hline $\begin{array}{l}\text { Children's alexithymia } \\
\text { Predictor }\end{array}$ & $\begin{array}{l}\text { Parents' alexithymia } \\
\text { Mediator }\end{array}$ & $\begin{array}{l}\text { Children's quality of life } \\
\text { Outcomes }\end{array}$ \\
\hline \multirow[t]{2}{*}{ Difficulty identify feelings } & Difficulty identify feelings & $\begin{array}{l}\text { Psychological well-being } \\
\text { Moods and emotions } \\
\text { Self-perception } \\
\text { Financial resources }\end{array}$ \\
\hline & Difficulty describing feeling & $\begin{array}{l}\text { Psychological well-being } \\
\text { Moods and emotions } \\
\text { Self-perception } \\
\text { Autonomy } \\
\text { Financial resources } \\
\text { School environment }\end{array}$ \\
\hline \multirow[t]{2}{*}{ Difficulty describing feeling } & Difficulty identifying feelings & $\begin{array}{l}\text { Psychological well-being } \\
\text { Moods and emotions } \\
\text { Self-perception } \\
\text { Financial resources }\end{array}$ \\
\hline & Difficulty describing feeling & $\begin{array}{l}\text { Psychological well-being } \\
\text { Moods and emotions } \\
\text { Self-perception } \\
\text { Autonomy } \\
\text { Financial resources } \\
\text { School environment }\end{array}$ \\
\hline
\end{tabular}


As suggested by Baron and Kenny (1986), ordinary least squares multiple regression is an appropriate method for determining the presence of mediating effects when the dependent variables are continuous and multiple predictor variables are present. When the preconditions have been fulfilled, the final step consists of showing that the strength of the association between childhood alexithymia dimensions and children's quality of life dimensions are significantly reduced when the mediating variable (parental alexithymia dimensions) is added to the regression model.

Partial mediation is demonstrated when the beta weight for the predictor variable is reduced (but not to non-significance) when the proposed mediator is added to the equation. Full mediation is demonstrated if the (beta) value for the predictor variable is reduced from significance to non-significance when the proposed mediator is added to the equation (Baron \& Kenny, 1986).Based on the observed correlations, we conducted hierarchical regression analyses on the various relevant outcome variables. Control variables (age) were entered in Step 1 in the case of DIF, childhood alexithymia dimensions were regressed on Step 2 (only those that had shown a significant relationship with the mediator variable), and parental alexithymia dimensions were entered in Step 3. The statistical analysis was conducted at a 95\% confidence level; $p<.05$ was considered statistically significant.

The analyses showed that parental DDF mediated the relationship between children's DIF and self-perception and financial resources. Also, parental DDF mediated the relationship between children's DDF and self-perception and financial resources (see Table 4). In all cases, the mediation effect was partial. 
Table 4. Mediation analysis. Predicting children's quality of life dimensions from DIF and DDF of parent's DDF (only significant findings are presented)

\begin{tabular}{|c|c|c|c|c|c|}
\hline SCL-90 dimensions & $\mathrm{F}$ & $\mathrm{R}^{2}$ & IncR $^{2}$ & Beta & $\mathrm{t}$ \\
\hline \multicolumn{6}{|l|}{ self-perception } \\
\hline Step 1: age & 0.112 & 0.000 & & -0.021 & -0.334 \\
\hline Step 2: children DIF & $20.546^{* *}$ & 0.131 & 0.047 & $-0.375\left(-0.346^{* *}\right)^{\mathrm{a}}$ & $-6.400 * *$ \\
\hline Step 3: parents DDF & $15.076^{* *}$ & 0.140 & 0.046 & -0.115 & $-1.995^{*}$ \\
\hline \multicolumn{6}{|l|}{ financial resources } \\
\hline Step 1: age & $14.092 * *$ & 0.052 & & 0.228 & $3.754 * *$ \\
\hline Step 2: children DIF & $13.184 * *$ & 0.093 & 0.425 & $-0.206\left(-0.170^{* *}\right)^{\mathrm{a}}$ & $-3.419 * *$ \\
\hline Step 3: parents DDF & $10.937 * *$ & 0.114 & 0.016 & -0.148 & $-2.437 *$ \\
\hline \multicolumn{6}{|l|}{ self-perception } \\
\hline Step 2: children DDF & $21.185 * *$ & 0.075 & 0.091 & $-0.273(-0.240 * *)^{\mathrm{a}}$ & $-4.603 * *$ \\
\hline Step 3: parents DDF & $13.138 * *$ & 0.091 & 0.057 & -0.133 & $-2.188^{*}$ \\
\hline \multicolumn{6}{|l|}{ financial resources } \\
\hline Step 1: age & $13.510 * *$ & 0.049 & & 0.222 & $3.676 * *$ \\
\hline Step 2: children DDF & $13.954 * *$ & 0.097 & 0.048 & $-0.219\left(-0.186^{* *}\right)^{\mathrm{a}}$ & $-3.706 * *$ \\
\hline Step 3: parents DDF & $11.199 * *$ & 0.115 & 0.059 & -0.138 & $-2.288^{*}$ \\
\hline
\end{tabular}

NOTE: Standardized regression coefficients (betas) are derived from the step in which they are added to the equation. DIF: Difficulty identify feelings, DDF: Difficulty describing feelings a. Beta value after introduction of parents DDF *p<0.05; ** $<<0.01$ 


\section{Discussion and Conclusions}

The results of this study indicate that there is a significant relation between parental alexithymia and childhood alexithymia. Specifically, there are high correlations between DIF and DDF in parents and children, but no relationship was observed between the dimensions of EOT.

Furthermore, the conceptual structure of the adult alexithymia appeared to differ from childhood alexithymia. EOT seems to acquire relevance in adult samples, whereas in samples of children it doesn't seem to be a fundamental element of the construct, nor have a role in relation to the prediction of the quality of life.

In adult samples, the reliability and validity of the three-factor structure has been established in several studies. However, DIF and DDF factors show good psychometric properties (Taylor \& Bagby, 2004) but EOT factor appears to be weak (Grabe et al., 2004). Studies in children samples are much scarcer. The first adaptation of the TAS-20 questionnaire for children (Alexithymia Questionnaire for children AQC; Rieffe et al., 2006), identified the three-factor structure of alexithymia, although the EOT factor showed low factor loadings and a low reliability. DIF and DDF factors contributed to the prediction of self-reported somatic complaints in children, but the EOT factor failed to do so. Loas et al. (2010) found similar results with the French version of the AQC. In the Farsi ACQ version (Rieffe et al., 2010), EOT factor was omitted (due to the poor psychometric properties and predictive validity) and the two remaining factors (DIF and DDF) were taken together.

Our results confirm the high relationship between DIF and DDF, and the possibility to see them as a single measure of alexithymia in children samples. The item structure of the DIF factor would be referring to the identification of physiological emotion phenomena and the DDF to the identification of the subjective feelings, and carrying an implicit communication component to another. Perhaps, the meaningful correlation found between the two factors (DIF and DDF) may be explained, especially in children, to the close relationship between emotional identification and communication. Moreover, according to the results, the predictive role of EOT is null on children's quality of life. 
With regards to the relationship of alexithymia and gender, our results are not significant. For adults, in general, results showed that men exhibited higher levels of alexithymia (Mattila, Salminen, Nummi, \& Joukamaa, 2006). In the case of children, the results are much scarcer and not entirely conclusive, but the few studies conducted in samples of adolescents showed that girls had higher scores in comparison with boys (Joukamaa et al., 2007). However, given the characteristics of this developmental stage, the data obtained cannot be generalized to children.

Regarding the relationship of alexithymia and age, our study shows negative correlations between age and DIF. Given that our study sample is between 8 and 12 years, we would expect a higher emotional identification at a later developmental stage and an older ager. To our knowledge, no data exists on the relationship between alexithymia and age at this developmental stage. In adult population, despite the inconsistences of some studies, alexithymia was found to occur more frequently in the upper age ranges (middle and late adulthood) than in adolescence and early adulthood in clinical and normative samples (Moriguchi et al., 2007). It could be hypothesized that through adolescence, there is a decrease of alexithymia, reflecting the acquisition, consistent with the cognitive-emotional development, of emotional regulation patterns, including emotional identification and differentiation. In adulthood and old age, the positive relation of alexithymia with increasing age (Mattila et al., 2006), could be due to cultural factors and not to developmental factors.

One of the findings observed in the literature with adult samples is a direct relationship of alexithymia with internalizing symptoms (Bagby et al., 1994). However, the literature on childhood alexithymia is not as abundant. Also it should be noted that, as mentioned, most of the studies are retrospective, being performed mostly in adult clinical populations with different pathologies (Pedrosa et al., 2008, Gil et al., 2009; Spitzer et al., 2009). The few studies that support the relationship between alexithymia and somatization in children have been conducted in children with physical and mental pathology compared to healthy children (DalZotto et al., 2011; Hosseinzadeh et al., 2013; Loas et al., 2012; Mishra et al., 2012).

With the available data in healthy children, there doesn't seem to be a confirmation of the hypothesis that there is a relationship between alexithymia and somatization. Although results are not conclusive (Rieffe et al., 2010), most studies conducted on healthy children 
(Jellesma et al., 2009; Nasiri et al., 2009) consider that there is a decisive role of negative moods (depression, anxiety) as mediating variables between alexithymia and complaints, at least for two dimensions of alexithymia (DDF and DIF) (Allen et al., 2011).

This lack of a direct relationship between physical complaints and alexithymia in healthy children is supported by the results of our work. Our results show the effect of DIF and DDF on all quality of life dimensions except the physical well-being dimension. In addition to the observations made above, it should be noted that the physical well-being dimension explores the level of the child's / adolescent's physical activity, energy and fitness (i.e. Have you felt fit and well?, Have you been physically active -running, climbing or biking-?), as a positive dimension that appears to be different from the concept of somatization. Moreover, the more predictive role (both for DIF and DDF) in quality of life, is obtained in predicting Moods and Emotions dimension, supporting the fact that the frequently found association between alexithymia and internalizing symptoms is actually mediated by mood states.

Our data shows a clear relationship between parental alexithymia and childhood alexithymia (DIF and DDF factors). Previous literature, except for some studies (Dal Zotto et al., 2011), supports this relationship in samples of children with some form of pathology (Guttman \& Laporte, 2002; Mishra et al., 2012; Szatmari et al., 2008). In samples of healthy children although few studies are focused on this, some studies have also pointed out the existing relations between alexithymia scores of mothers and children (Luminet \& Lenoir, 2007), or other family members. Mahler et al. (2011) revealed that the mothers' alexithymia and the fathers' alexithymia independently predict their children's alexithymia.

Finally, regarding the mediating role of parental alexithymia between childhood alexithymia and different children's quality of life scales, it is important to state that in previous literature this has hardly been explored. Our data suggest that parental alexithymia, especially parental DDF, is a fundamental mediator in the relationship between children's DIF/ DDF and some children's quality of life dimensions (self-perception and financial resources).

This paper presents some limitations that should be highlighted. The presence of bias in the sample with regard to its population can be explained by the use of non-probability ac- 
cidental sampling. This circumstance can alter the findings of the study as a result of homogeneity of the children in our sample. Given that the current study was cross-sectional, we cannot make inferences about causality. In order to determine whether alexithymia influences quality of life, longitudinal studies are needed. The translation of the original ACQ into Spanish should have been accomplished through simultaneous translation by several researchers and subsequent analysis of convergence among them, and not through a process of reverse translation of native language experts. However, it should be noted that the wording and syntax of the original items, as well as the vocabulary used, are extremely simple and easily understandable, which can greatly reduce the potential biases in the Spanish adaptation created by this procedure. A limitation of the design was that the detection of quality of life as well as the assessment of alexithymia was made on the basis of self-reported evaluations, which may have caused a certain bias. Future researchers should also use more sophisticated measures of such constructs such as structured clinical interviews, peer or family ratings, and direct behavioral assessments.

In summary, the present study shows, in healthy children, the relation between parental alexithymia and childhood alexithymia, and how parental alexithymia can increase the previously suggested effect of childhood alexithymia on quality of life. Also, we should reiterated that contrary to previous studies, we have chosen so use health indicators instead of symptoms, as Nasiri et al. (2009).

Our results have important practical implications. Within an educational system according to competences, programs dedicated both to parental emotional education, where alexithymia is addressed, as well as emotional regulation in children (especially in aspects referred to appropriate emotional expression) should be incorporated into the curriculum of schools to guarantee children's wellbeing, as well as for the prevention of this disorder in adulthood. 


\section{References}

Allen, L. B., Lu, Q., Tsao, J. C. I., Hayes, L. P., \& Zeltzer, L. K. (2011). Depression partially mediates the relationship between alexithymia and somatization in a sample of healthy children. Journal of Health Psychology, 16(8), 1177-1186. DOI: 10.1177/1359105311402407

Aymerich, M., Berra, S., Guillamón, I., Herdman, M., Alonso, J., Ravens-Sieberer, U., \& Rajmil, L. (2005). Desarrollo de la versión en español del KIDSCREEN, un cuestionario de calidad de vida para la población infantil y adolescente. [Development KIDSCREEN Spanish version, a questionnaire of quality of life for children and adolescents]. Gaceta Sanitaria, 19, 93-102. DOI: $10.1157 / 13074363$

Aust, S., Hartwig, E. A., Heuser, I., \& Bajbouj, M. (2013). The role of early emotional neglect in alexithymia. Psychological Trauma: Theory, Research, Practice, and Policy, 5(3), 225-232. DOI: $10.1037 / \mathrm{a} 0027314$

Bagby, R., Parker, J., \& Taylor, G. (1994). The twenty-item toronto Alexithymia Scale: I. item selection and cross-validation of the factor structure. . J Psychosom Res, 38, 23- 32. DOI: 10.1016/0022-3999(94)90005-1

Baron, R. M., \& Kenny, D. A. (1986). The moderator-mediator variable distinction in social psychological research: Conceptual, strategic, and statistical considerations. Journal of Personality and Social Psychology, 51, 1173-1182.

Dal Zotto, L., Toldo, I., Sartori, S., Battistella, P. A. (2011). Alexithymia in juvenile primary headache sufferers: A pilot study. The Journal of Headache and Pain, 12, 71-80. DOI: 10.1007/s10194010-0248-6

De Gucht, V., \& Heiser, W. (2003). Alexithymia and somatisation: A quantitative review of the literature. Journal of Psychosomatic Research, 54(5), 425-434. DOI: 10.1016/S0022-3999(02)00467-1

De Rick, A., \& Vanheule, S. (2006). The relationship between perceived parenting, adult attachment style and alexithymia in alcoholic inpatients. Addictive Behaviors, 31(7), 1265-1270. DOI: 10.1016/j.addbeh.2005.08.010

Dial Ward, M. D. (2002). Parental affective expressiveness and patterns of alexithymia in men and women. Dissertation Abstracts International: Section B: The Sciences and Engineering, 62 (11B), 5369 . 
Evren, C., Evren, B., Dalbudak, E., Ozcelik, B., \& Oncu, F. (2009). Childhood abuse and neglect as a risk factor for alexithymia in adult male substance dependent inpatients. Journal of Psychoactive Drugs, 41(1), 85-92. DOI: 10.1080/02791072.2009.10400677

Gil, F. P., Scheidt, C. E., Hoeger, D., \& Nickel, M. (2008). Relationship between attachment style, parental bonding and alexithymia in adults with somatoform disorders. International Journal of Psychiatry in Medicine, 38(4), 437-451. DOI: 10.2190/PM.38.4.d

Grabe, H.J., Spitzer, C., \& Freyberger, H.J. (2004). Alexithymia and Personality in Relation to Dimensions of Psychopathology. Am $J$ Psychiatry, 161,1299-1301. DOI: 10.1176/appi.ajp.161.7.1299

Guttman, H., \& Laporte, L. (2002). Alexithymia, empathy, and psychological symptoms in a family context. Comprehensive Psychiatry, 43(6), 448-455. DOI: 10.1053/comp.2002.35905

Holmbeck, G. N. (1997). Toward terminological, conceptual, and statistical clarity in the study of mediators and moderators: Examples from the child-clinical and pediatric psychology literatures. Journal of Consulting and Clinical Psychology, 65, 599-610. DOI: 10.1037/0022-006X.65.4.599

Hosseinzadeh, A. A., Hooman, H. A., Salehi, M., \& Kooshki, S. (2013). Maternal bonding and vulnerability related to eating: The mediational role of eating disorder beliefs and alexithymia. Journal of Iranian Psychologists, 9(34), 129-142.

Jellesma, F. C., Rieffe, C., Terwogt, M. M., \& Westenberg, M. (2009). Do I feel sadness, fear or both? comparing self-reported alexithymia and emotional task-performance in children with many or few somatic complaints. Psychology \& Health, 24(8), 881-893. DOI: 10.1080/08870440801998970

Joukamaa, M., Kokkonen, P., Veijola, J., Laksy, K., Karvonen, J. T., Jokelainen, J., \& Jarvelin, M. (2003). Social situation of expectant mothers and alexithymia 31 years later in their offspring: A prospective study. Psychosomatic Medicine, 65(2), 307-312. DOI: 10.1097/01.PSY.0000030389.53353

Joukamaa, M., Luutonen, S., Von Reventlow, H., Patterson, P., Karlsson, H., \& Salokangas, R. K. R. (2008). Alexithymia and childhood abuse among patients attending primary and psychiatric care: Results of the RADEP study. Psychosomatics: Journal of Consultation Liaison Psychiatry, 49(4), 317-325. DOI: 10.1176/appi.psy.49.4.317

Joukamaa, M., Taanila, A., Miettunen, J., Karvonen, J. T., Koskinen, M., \& Veijola, J. (2007). Epidemiology of alexithymia among adolescents. Journal of Psychosomatic Research, 63(4), 373-376. DOI: 10.1016/j.jpsychores.2007.01.018

Keskin, G., \& Bilge, A. (2009). The evaluation of depression, social anxiety, alexithymia on children and adolescent with chronic renal failure. Anadolu Psikiyatri Dergisi, 10(4), 318-324.

Loas, G., Dugré-Lebigre, C., Fremaux, D., Verrier, A., Wallier, J., Berthoz, S., Corcos, M. (2010). The Alexithymia Questionnaire for Children (AQC): French translation and validation study in a convenience sample of 80 children. L'Encéphale, 26, 302-306. DOI: 10.1016/j.encep.2009.06.009 
Loas, G., Speranza, M., PhamScottez, A., Perez Diaz, F., \& Corcos, M. (2012). Alexithymia in adolescents with borderline personality disorder. Journal of Psychosomatic Research, 72(2), 147152. DOI: 10.1016/j.jpsychores.2011.11.006

Luminet, O., \& Lenoir, V. (2006). Parents' alexithymia and their 3-5 years-old children's emotional abilities. Enfance, 58(4), 335-356.

Mahler, J., Barnow, S., Freyberger, H. J., Spitzer, C., \& Grabe, H. J. (2009). Familial transmission of alexithymia. PDP Psychodynamische Psychotherapie: Forum Der Tiefenpsychologisch Fundierten Psychotherapie, 8(1), 3-11. DOI: 10.1016/j.eurpsy.2008.01.140

Mattila, A.K., Salminen, J.K., Nummi, T., Joukamaa, M. (2006).Age is strongly associated with alexithymia in the general population. Journal of Psychosomatic Research. 61(5),629-35. DOI: 10.1016/j.jpsychores.2006.04.013

Mishra, V. S., Maudgal, S., Theunissen, S. C. P. M., \& Rieffe, C. (2012). Alexithymia in children with cancer and their siblings. Journal of Psychosomatic Research, 72(4), 266-268. DOI: 10.1016/j.jpsychores.2011.12.007

Moriguchi, Y., Maeda, M., Igarashi, T., Ishikawa, T., Shoji, M., Kubo, C., Komaki, G. (2007). Age and gender effect on alexithymia in large, Japanese community and clinical samples: a crossvalidation study of the Toronto Alexithymia Scale (TAS-20). In-Process \& Other Non-Indexed Citations BioPsychoSocial Medicine.1,7. DOI: 10.1186/1751-0759-1-7

Nasiri, H., Latifian, M., \& Rieffe, C. (2009). Alexithymia and its relationship with physical complaints and emotional competency in children and adolescents. Iranian Journal of Psychiatry and Clinical Psychology, 15(3), 248-257. DOI: 10.1186/s10194-016-0640-y

Páez, D., Velasco, C. \& Gonzalez, J. L. (1999). Expressive writing and the role of alexythimia as a dispositional deficit in self-disclosure and psychological health. Journal of Personality and Social Psychology, 77, 630-641. DOI: 10.1037/0022-3514.77.3.630

Preacher, K. J., Rucker, D. D., \& Hayes, A. F. (2007). Addressing moderated mediation hypotheses: Theory, methods, and prescriptions. Multivariate Behavioral Research, 42, 185-227. DOI: $10.1080 / 00273170701341316$

Pedrosa, F., Weigl, M., Wessels, T., Irnich, D., Baumuller, E., \& Winkelmann, A. (2008). Parental bonding and alexithymia in adults with fibromyalgia. Psychosomatics: Journal of Consultation Liaison Psychiatry, 49(2), 115-122. DOI: 10.1176/appi.psy.49.2.115

Ravens-Sieberer, U., Gosch, A., Rajmil, L., Erhart, M., Bruil, J., Duer, W., Auquier, P., Power, M., Abel, T., Czemy, L., Mazur, J., Czimbalmos, A., Tountas, Y., Hagquist, C., Kilroe, J. and the European KIDSCREEN Group. (2005). KIDSCREEN-52 quality-of-life measure for children and adolescents. Expert Review of Pharmacoeconomics \& Outcomes Research, 5, 353 364. DOI: 10.1586/14737167.5.3.353 
Rieffe, C., Oosterveld, P., Meerum Terwogt, M. (2006). An alexithymia questionnaire for children: Factorial and concurrent validation results. Personality and Individual Differences, 40, 123-133. DOI: 10.1016/j.paid.2005.05.013

Rieffe, C., Oosterveld, P., Meerum Terwogt, M., Novin, S., Nasiri, H., \& Latifian, M. (2010). Relationship between alexithymia, mood and internalizing symptoms in children and young adolescents: Evidence from an iranian sample. Personality and Individual Differences, 48(4), 425-430. DOI: $10.1016 /$ j.paid.2009.11.010

Sifneos, P.E. (1973). The prevalence of alexithymic characteristics in psychosomatic patients. Psychother Psychosom, 22, 255-62. DOI: 10.1159/000286529

Spitzer, C., Busche, W., Vogel, M., Barnow, S., Freyberger, H. J., \& Grabe, H. J. (2009). Parenting, childhood maltreatment and alexithymia. PDP Psychodynamische Psychotherapie: Forum Der Tiefenpsychologisch Fundierten Psychotherapie, 8(1), 13-22.

Sobel, M. E. (1982). Asymptotic confidence intervals for indirect effects in structural equation models. In S. Leinhardt (Ed.), Sociological methodology 1982 (pp. 290-312). Washington DC: American Sociological Association. DOI: 10.2307/270723

Szatmari, P., Georgiades, S., Duku, E., Zwaigenbaum, L., Goldberg, J., \& Bennett, T. (2008). Alexithymia in parents of children with autism spectrum disorder. Journal of Autism and Developmental Disorders, 38(10), 1859-1865. DOI: 10.1007/s10803-008-0576-4

Taylor, G.J., \& Bagdy, R.M. (2004). New Trends in Alexithymia. Research. Psychotherapy and Psychosomatics, 73, 68-77. DOI: 10.1159/000075537

Thorberg, F. A., Young, R. M., Sullivan, K. A., \& Lyvers, M. (2011). Parental bonding and alexithymia: A meta-analysis. European Psychiatry, 26(3), 187-193. DOI: 10.1016/j.eurpsy.2010.09.010

Van de Putte, Elise M, Engelbert, R. H. H., Kuis, W., Kimpen, J. L. L., \& Uiterwaal, C. S. P. M. (2007). Alexithymia in adolescents with chronic fatigue syndrome. Journal of Psychosomatic Research, 63(4), 377-380. DOI: 10.1016/j.jpsychores.2007.07.009 